\title{
Synthesis and Identification of Some Complexes of 4-[N-(2,4- Dihydroxybenzylidene) imino] Antipyrinyl with Serine (L1) or with Theronine (L2) Ligands and Evaluation of Their Bacteria Activities
}

\author{
Amerah Jihad Al-Shaheen ${ }^{1 *}$, Abdallah Fathi Al- Bergas ${ }^{2}$ \\ ${ }^{1,2}$ Department of Chemistry, College of Education of Pure Science, University of Mosul, Mosul, Iraq \\ E-mail: ${ }^{1 *}$ amiraalshaheen@uomosul.edu.org, ${ }^{2}$ abdallahyamancheme@ yahoo.com
}

(Received March 24, 2020; Accepted May 11, 2020; Available online December 01, 2020)

DOI: 10.33899/edusj.2020.126837.1058, (c) 2020, College of Education for Pure Science, University of Mosul.

This is an open access article under the CC BY 4.0 license (http://creativecommons.org/licenses/by/4.0/).

\begin{abstract}
:
This work involves the preparation new ligands 4-[N- (2,4-Dihydroxybenzylidene) imino] antipyrinyl Serine (L1) or with Theronine (L2) . from these ligands ,ten Complexes have been synthesized with metal ions $\mathrm{Co}$ (II) , Ni(II) $\mathrm{Cu}$ (II) $\mathrm{Zn}$ (II) and $\mathrm{Cd}$ (II) in molar ratio (1:1) Metal: Ligand and these complexes have been characterized on the basis of physiochemical,investigations $\left({ }^{1} \mathrm{HNMR}\right)$,(IR) electronicspectroscopy(U.V-Vis), molar conductance, magnetic moment measurement, Thermal analysis (TGA), ,elemental analysis, Powder X-ray diffraction and spectral studies. Infrared data suggest that the ligands( L1) and( L2) behave as tetradentate ligands and coordinated through $(\mathrm{N}, \mathrm{N}, \mathrm{O}, \mathrm{O})$ as adonor atoms sequence towards the metal ions, and they give an square planer and tetrahedral complexes, finally some of these prepared complexes have been screened for their antibacterial activities against two classes of human pathogenic; bacteria Gram positive eg: Staphylococcus.aureus, and Gram negativebacteria including,Pseudomonas,aeruginosa, Klebsiella pneumoni and.Escherichiacoli, The performance results explain that the metal complexes have greater action more essential than the free ligands
\end{abstract}

Keywords: Serine, Theronine ,4-amino Antipyrine Complexes.

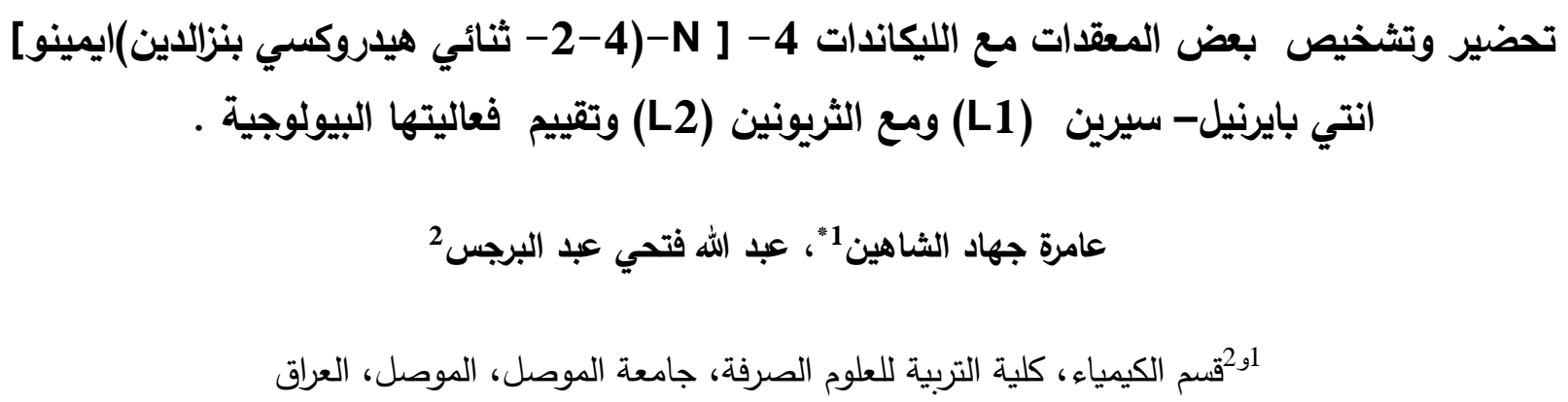

الخلاصة:

في هذه الدراسة حَضرتْ ليكاندات الجديدة 4 -N]-N (2.4 ثنائي هيدروكسي بنزالدين) ايمينو] انتي بايرنيل مع سيرين (L1) أو مع

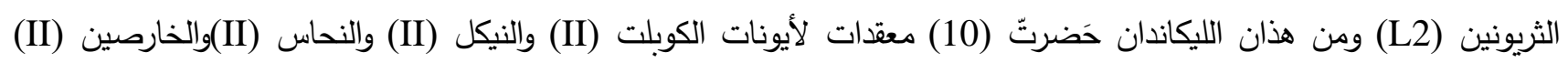
والكادميوم (II) وبنسبة مولارية (1:1) (فلز : ليكاند) وُشخصَتّ المعقدات المحضرة باستعمال تقنيات كيميائية وفيزيائية طيفية مختلفة 
منها أطياف الأشعة تحت الحمراء وقياس طيف الرنين النووي المغناطيسي للبروتون , والأطياف الاككترونية ,والعزم المغناطيسي, والتوصيلية المولارية ,والتحليل الدقيق للعناصر , وحيود الأشعة السينية للمسحوق ,وفحص بالتحاليل الحرارية , وبينت الدراسات أعلاه ومن ضمنها الدراسات الطيفية (IR) بان الليكاندان (L2) \& تسلك سلوك ليكاندات رباعية السن تتناسق مع الأيون الفلزي من خلا ذرات (N,N,O,O) على التعاقب وأعطت معقدات مربع مستوي ورباعي السطوح , وأخيرا درُسَتّ الفعالية البيولوجية لليكاندين وبعض معقداتهم, على نوعين من البكتريا الممرضى للإنسان الموجبة لصبغة كرام,Staphylococcus.aureus والسالبة لصبغة كرام التي تضم بكتريا Eseudomonas aeroginosa و E. coli

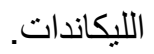

الكلمات الدالة: سيرين , ثريونين, معقدات 4 -امينو انتي بايرين,.

\section{Introduction}

المقدمة : (المقا

يعتبر المركب 4- امينوانتي بايرين من المركبات الحلقية غير المتجانسة التي تدخل في تركيب معظم الفيتامينات مثل فيتامين (C) التي لها حلقات تحتوي على النيتروجين والأوكسجين، لذلك نالت ليكاندات الانتي بايرين, اهتماما كبيرا في السنوات الأخيرة من الناحيتين البيولوجية والكيميائية [1], ولقد بينت الدراسات التي أجريت على معقداتها إن لها عدة تطبيقات صناعية في تحضير البوليمرات ومرافقات إنزيمية ومبيدات حشرية وللديدان ومنظمات نمو للنباتات [2] واستعملت كثرا في صناعات

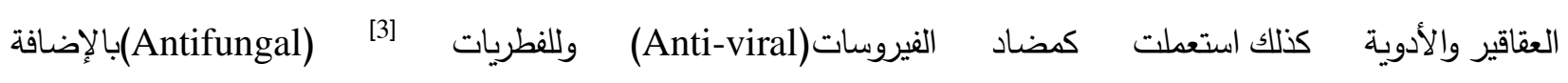

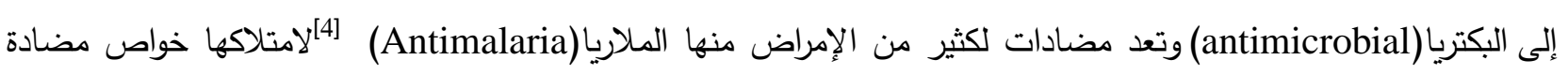
للالتهاب(Antibiotic) وتستعمل كعوامل مضادة لمرض السكري(ant diabetic) فضلا عن ذلك فعاليتها ضدا لأورام السرطان(Antitumor) و مضادات اكسدة تعمل على اطفاء الجذور الحرة (Antioxidant) ودرسها بشكل واسع لما لها من تطبيقات صناعية وصفات حياتية' في الوقت الحاضر نظرا لامتلاكها المجموعة الفعالة (C=N-) الازوميثين المجموعة الفعالة التي جعلت من قواعد شيف تدخل في كثير من التطبيقات, فهي تمتلك خاصية نقل الأوكسين باعتبارها مركبات كليتية مع العناصر الانتقالية الموجودة في الخلايا الحية [5] فئ.

\section{Materials and Methods}

المواد وطرائق العمل : 1- المواد الكيميائية :جميع المواد الكيميائية المستخدمة في الدراسة مجهزة من شركة Sigma-Aldrich-BDH - Fluka-بدون تتقية اضافية.

\section{Instrument \& Measurment}

: 2- 2 - 2 الأجهزة و القياسات

ق مُِِتَت درجات الانصهار أو التفكك لليكاندات و للمعقدات في قسم الكيمياء/كلية التربية للعلوم الصرفة /جامعة الموصل باستعمال جهاز (Melting point Apparatus) موديل (SMP30) والمصنع من قبل شركة Scientific) Limited Bibby) سنة (2003)أما القياسات المغناطيسية للمعقدات تم استعمل جهاز كوي (Magnetic Susceptibility. Balance) , أما الأطياف الأشعة تحت الحمراء سجلت لليكاند ومعقداته في كلية الصيدلة /جامعة الموصل باستعمال جهاز الماني -Bruker Alpha- ATR) 
فTIR ) التوصيلية الكهربائية ومن نوع (Eutech, pc 700) وباستعمال مذيب ثنائي مثيل فورماميد بتركيز ( $)$ (10 M مولاري وعند درجة حرارة ( 25) م وسُجِلتُ الأطياف الاككترونية للمعدات للأشعة فوق البنفجية والمرئية بجهاز (U.V) في كلية التربية للعلوم الصرفة - جامعة الموصل, في درجة حرارة الغرفة وباستعمال جهاز(U.VShamadzu-visible1800spectro photometer) وباستعمال مذيب ثنائي مثيل فورماميد وتم القياس باستعمال خلايا كوارتز التي قطرها (1) سم في المدى(anm 200 - 1100 ) تم تحديد كمية العناصر الفلزية في المعقدات باستخدام مطيافية الامتصاص الذري حيث قيست النماذج في مركز البحوثاكلية الزراعة - جامعة الموصل باستعمال جهاز من نوع (NovAA anlitjena) . وقيست التحاليل الحرارية عند درجة حرارة (Co -25) بجهاز (Mattler Toledo) لبعض المعقدات المحضرة في قسم العلوم- كلية التربية الأساسية - جامعة الموصل. كما تم قياس التحليل الدقيق للعناصر (CHN) لليكاندات المحضر وكذلك للمعقدات باستعمال جهاز التحليل الدقيق للعناصر من نوع Xrd ( جuroE A 3000 / Italy ) (x,pert Phillips Holland /إيران بجهاز من نوع (Varian Agilant500 Mhz) أمريكي الصنع ودرست الفعالية البيولوجية لليكاندات والمعقدات المحضرة في قسم علوم الأحياء/ المجهرية- كلية التربية/ جامعة الموصل.

\section{3- طرائق العمل: \\ ${ }^{[6,7,8]} \mathbf{L}_{\mathbf{1}}\left(\mathrm{K}_{4}\right.$-Adhbser $) \mathbf{L}_{\mathbf{2}}$, (K4-AdhbThr) \\ تحضير الليكاندان}

potassium 2-[(4-(2,4-dihydroxybenzylidene)amino]-1,5- dimethyl-2- phenyl-1,2-dihydro-3H(pyrazol-3- ylidene)amino)-3- hydroxypropanoate L1)

potassium 2-[-4-(2,4-dihydroxybenzylidene)amino)]-1,5-dimethyl-2-phenyl-1,2-dihydro-3H( pyrazol-3-ylidene)amino)-3-hydroxybutanoate L2)

الخطوة الاولى: أضيف (2.760 g , 0.02 mol (4.064 g 0.02 mol) من- أمينو أنتي بايرين إلى محلول مكون من إذابة ( من (2-4 ثنائي هيدروكسي بنز الديهايد ) في (50 ml) من الايثانول المطلق في دورق زجاجي سعة 250mL, حُرك للمزيج مع التصعيد الحراري لمدة ثلاث ساعات لوحظ ظهور راسب ثم ترك المحلول إلى اليوم الثاني لكي يستقر ثم رشح الراسب وُغسل بالايثانول

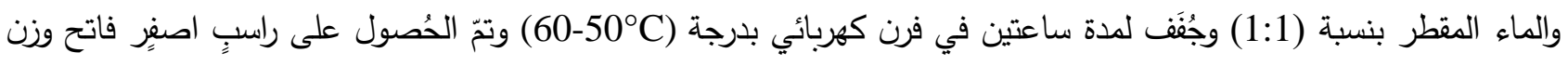
وكانت النسبة المئوية للناتج = 81\% ودرجة الانصهار = 233C-230 والمعادلة الآتية تُبين الخطوة الأولى من, تَحضير الليكاندين. 


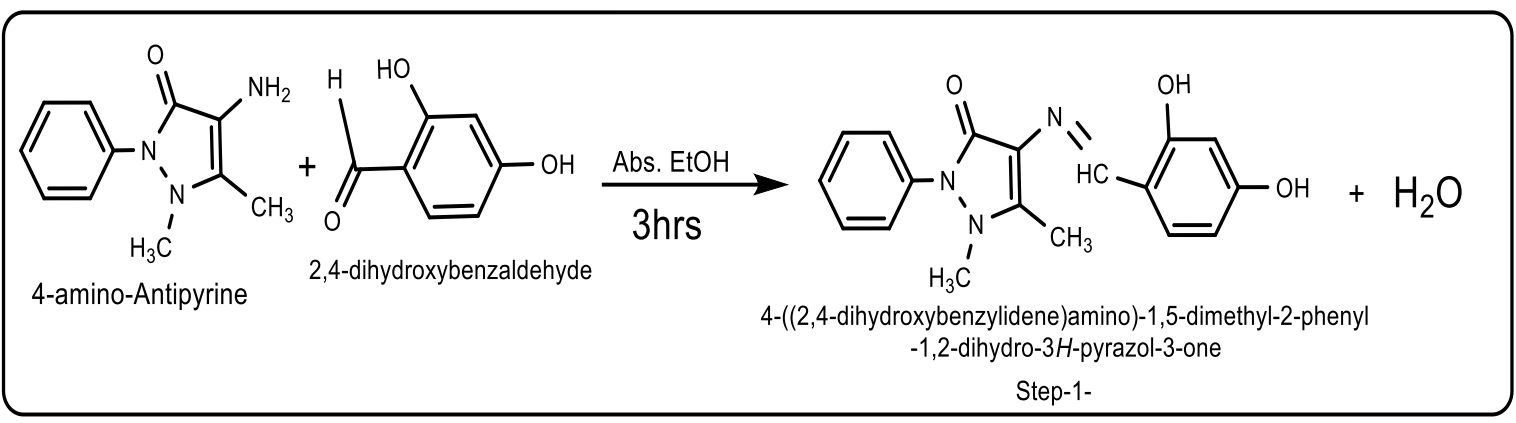

الخطوة الثانية: من تحضير الليكاندين (L2\& L1) تمت مُفاعلة الحامض الأميني سيرين 1.050 g 0.01mol) Serine) المذاب في(30mL) من محلول هيدروكسيد البوتاسيوم الكحولي ذي تركيز 0.56 g 0.01 mol) KOH) في بيكر وحرك المحلول إلى أن تمت الإذابة بالكامل بعد ذلك تم أضافته الى (3.233g 0.01mol) من قاعدة شيف المحضرة في الخطوة الاولى, المذابة في (40mL) من الايثانول المطلق في دورق زجاجي سعة (250mL) وحرك المزيج مع التصعد الحراري لمدة ثلاث ساعات, وُظهور راسبٍ, ترك المحلول إلى اليوم الثاني لكي يستقر ثم رشح وُغَل بالايثانول والماء المقطر بنسبة (1:1) وجفف لمدة ساعتين في فرن كهربائي بدرجة (50CC الأنصهار للناتج لليكاند الاول =(270-273C),أما فيما يخص الليكاند الثاني حُضرَ من الحامض الاميني Theronine مع الجزء الأول من الليكاند في المرحلة الأولى , وتم مُفاعلته مع (30mL Theronine 1.190 g 0.01mol ) لحامض الثذاب في الثرنين محلول هيدروكسيد البوتاسيوم الكحول ذي تركيز 0.56 g 0.01 mol)KOH) وقاعدة شيف في الخطوة الأولى, (0.01mol 3.233g g المذاب (40mL) وأتباع نفس خطوات العمل من حيث المزج والتحريك والتصعيد وتم الحصول على الليكاند الثاني بشكل راسبٍ اصنفِر , وجُفَف وبعد ذلك وزن وكان بنسبة ناتج = 79\%, ودرجة الانصهار = (234C-234C) والمعادلات التالي تُبيَن عملية تُحضير الجزء الثاني من قاعدة شيف , والجدول رقم (2) يوضح التحليل الدقيق للعناصر (C.H.N) لهذين الليكاندين.

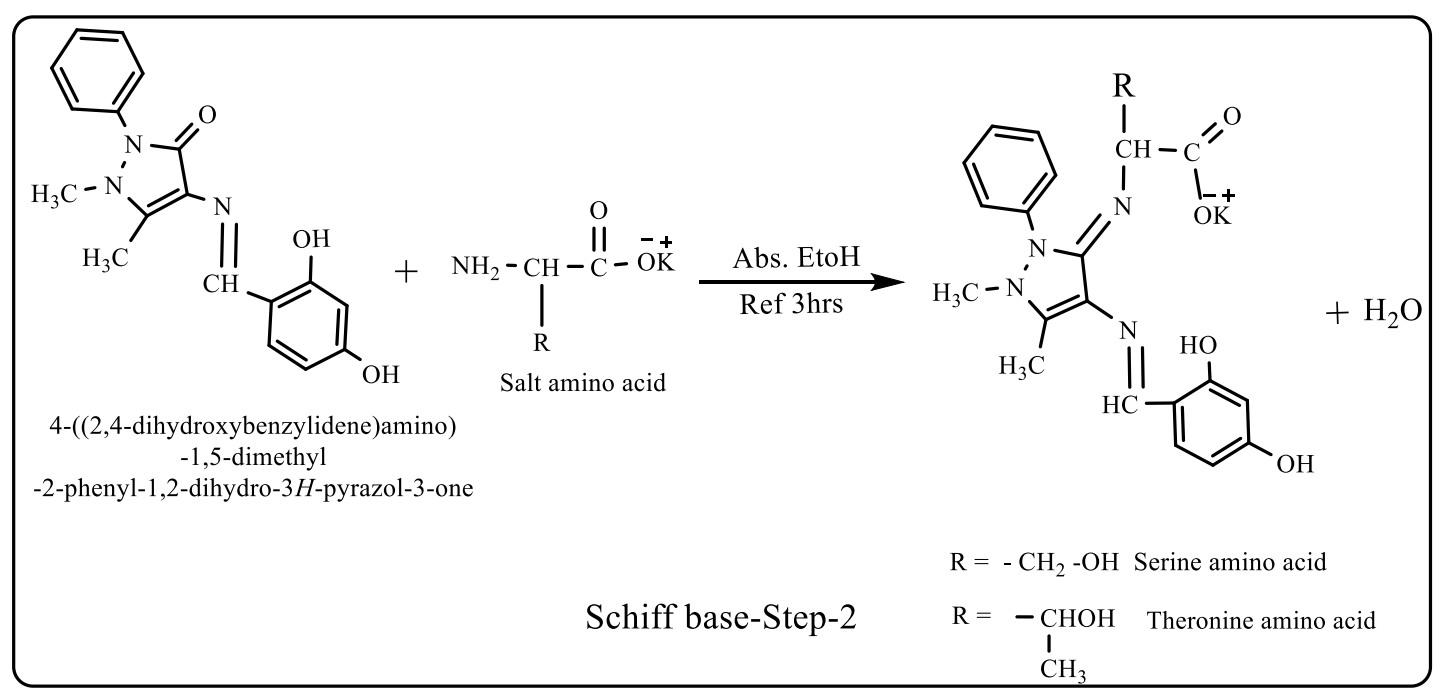


Preparation of the Complexes

حُضِرتّ المعقدات بإتباع الطرائق المنشورة في الأدبيات][7,8] وحضرت معقدات الكوبلت(II) ,النيكل(II),النحاس(II) , الخارصين

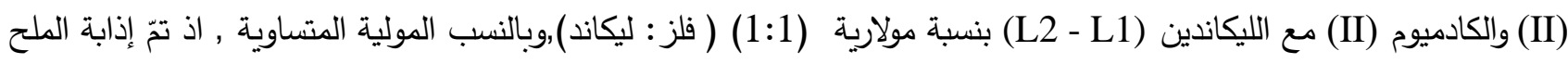
الفلزي (0.004 mol) في (20 ml) من الايثانول ثم أُضُيف إلى (20 mL) من الليكاند المذاب في الايثانول, ثُّ صُعَد المزيج لمدة ساعة وبُرَد ورشح الراسَب المتكون وُغَسل بالأيثر البترولي و جُفقت الرواسب وتم تشخيصها كما في الجدولين رقم (2,3)

الجدول (1) يبين بعض الخواص الفيزيائية وأوزان الليكاندين والأملاح المستخدمة في تَحضُير معقداتهما .

\begin{tabular}{|c|c|c|c|c|c|c|}
\hline رقعت & ملح الفلز & الفزي(غئح) & الليكاند(غم) & صيغة المعقد المقترح & Cالانصهةر & اللون \\
\hline 1 & $\mathrm{CoCl}_{2} 6 \mathrm{H}_{2} \mathrm{O}$ & 1.07 & 2.01 & [Co(4-AdHb-Ser)] & $262-266$ & ازرق مخضر \\
\hline 2 & $\mathrm{NiCl}_{2} \cdot 6 \mathrm{H}_{2} \mathrm{O}$ & 1.06 & 2.01 & [Ni(4-AdHb-Ser )] & $260-263$ & اخضر فاتح \\
\hline 3 & $\mathrm{CuCl}_{2} 2 \mathrm{H}_{2} \mathrm{O}$ & 0.76 & 2.01 & [Cu(4-AdHb-Ser )] & $256-258$ & بني غامق \\
\hline 4 & $\mathrm{ZnCl}_{2} \cdot 6 \mathrm{H}_{2} \mathrm{O}$ & 1.09 & 2.01 & [Zn(4-AdHb-Ser )] & $283-286$ & اصفر غامق \\
\hline 5 & $\mathrm{CdCl}_{2} \cdot 6 \mathrm{H}_{2} \mathrm{O}$ & 1.31 & 2.01 & [Cd4-AdHb-Ser )] & $225-228$ & اصفر غامق \\
\hline 6 & $\mathrm{CoCl}_{2} \cdot 6 \mathrm{H}_{2} \mathrm{O}$ & 1.07 & 2.08 & [Co(4-AdHb-Thr)] & $192-196$ & اخضر زيتوني \\
\hline 7 & $\mathrm{NiCl}_{2} \cdot 6 \mathrm{H}_{2} \mathrm{O}$ & 1.06 & 2.08 & [Ni(4-AdHb-Thr)] & $191-195$ & اخضر فاتح \\
\hline 8 & $\mathrm{CuCl}_{2} 2 \mathrm{H}_{2} \mathrm{O}$ & 0.76 & 2.08 & [Cu(4-AdHb-Thr $)]$ & $189-192$ & بني غامق \\
\hline 9 & $\mathrm{ZnCl}_{2} \cdot 6 \mathrm{H}_{2} \mathrm{O}$ & 1.09 & 2.08 & [Zn(4-AdHb-Thr )] & $245-248$ & اصفر فاتح \\
\hline 10 & $\mathrm{CdCl}_{2} 6 \mathrm{H}_{2} \mathrm{O}$ & 1.31 & 2.08 & [Cd(4-AdHb-Thr )] & $229-232$ & اصفر غامق \\
\hline
\end{tabular}


الجدول (2) يبين التحليل الدقيق للعناصر نظرياً (عملياً) لليكاندين ومعقداتهما وقيم التوصيلية المولارية للمعقدات

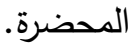

\begin{tabular}{|c|c|c|c|c|c|c|}
\hline \multirow{2}{*}{ No. } & \multirow{2}{*}{ Ligands / Complexes } & \multirow{2}{*}{$\frac{\left.\mathrm{ohm}^{-1} \mathrm{~cm}^{2} \mathrm{~mol}^{-1}\right)}{\mathrm{A}_{\text {作 }}}$} & \multicolumn{4}{|c|}{$\% \%$ Found (calc) } \\
\hline & & & $\mathbf{C}$ & $\mathbf{H}$ & $\mathbf{N}$ & $\mathbf{M}$ \\
\hline \multirow[b]{2}{*}{ - } & \multirow{2}{*}{$\mathrm{K}_{4}$-AdHb-Ser } & \multirow{2}{*}{--} & 56.24 & 4.72 & 12.49 & -- \\
\hline & & & $(56.52)$ & $(5.00)$ & $(12.70)$ & - \\
\hline \multirow{2}{*}{1} & \multirow{2}{*}{ [Co(4- AdHb-Ser )] } & \multirow{2}{*}{12.4} & 53.97 & 4.31 & 11.99 & 12.61 \\
\hline & & & $(54.08)$ & $(4.50)$ & $(12.07)$ & $(12.91)$ \\
\hline \multirow[b]{2}{*}{2} & \multirow{2}{*}{ [Ni(4- AdHb-Ser )] } & \multirow{2}{*}{13.2} & 54.00 & 4.32 & 11.99 & 12.57 \\
\hline & & & $(54.22)$ & $(4.60)$ & $(12.00)$ & (12.69) \\
\hline \multirow[b]{2}{*}{3} & \multirow[b]{2}{*}[\mathrm{Cu}(4-\mathrm{AdHb}-\mathrm{Ser})]{} & \multirow{2}{*}{17.5} & 53.44 & 44.27 & 11.87 & 13.46 \\
\hline & & & $(53.54)$ & $(4.60)$ & $(12.00)$ & (13.61) \\
\hline \multirow[b]{2}{*}{4} & \multirow[b]{2}{*}{ [Zn(4- AdHb-Ser )] } & \multirow{2}{*}{13.9} & 53.24 & 4.26 & 11.83 & 13.80 \\
\hline & & & $(53.32)$ & $(4.37)$ & $(11.90)$ & $(13.85)$ \\
\hline \multirow[b]{2}{*}{5} & \multirow{2}{*}{ [Cd(4- AdHb-Ser )] } & \multirow[b]{2}{*}{4.3} & 48.43 & 3.87 & 10.76 & 21.58 \\
\hline & & & $(48.50)$ & $(3.70)$ & $(10.98)$ & $(22.0)$ \\
\hline \multirow[b]{2}{*}{--} & \multirow{2}{*}{$\mathrm{K}_{4}$-AdHb-Thr } & \multirow[b]{2}{*}{--} & 57.13 & 5.01 & 12.11 & -- \\
\hline & & & $(57.70)$ & (5.13) & $(12.22)$ & - \\
\hline \multirow[b]{2}{*}{6} & \multirow{2}{*}{ [Co(4- AdHb-Thr )] } & \multirow[b]{2}{*}{8.4} & 54.89 & 4.61 & 11.64 & 12.24 \\
\hline & & & $\begin{array}{l}(54.96) \\
\end{array}$ & (4.71) & $(11.89)$ & $(12.31)$ \\
\hline \multirow{2}{*}{7} & \multirow{2}{*}{ [Ni(4- AdHb-Thr )] } & \multirow{2}{*}{14.3} & 54.92 & 4.61 & 11.64 & 12.20 \\
\hline & & & $(55.00)$ & $(4.82)$ & $(11.87)$ & (12.31) \\
\hline \multirow{2}{*}{8} & \multirow{2}{*}[\mathrm{Cu}(4-\mathrm{AdHb}-\mathrm{Thr})]{} & 103 & 54.37 & 4.56 & 11.53 & 13.08 \\
\hline & & 10.3 & $(54.45)$ & $(4.72)$ & $(11.87)$ & $(13.22)$ \\
\hline 0 & 7n(4-AdHb-Thr ) & 127 & 54.17 & 4.55 & 11.49 & 13.40 \\
\hline S & {$[\operatorname{Lin}(4-2 \pi 010-1110)]$} & 12.1 & $(54.21)$ & $(4.58)$ & $(11.54)$ & (13.46) \\
\hline 10 & [Cd(4-AdHh-Thr ) & 131 & 49.40 & 4.15 & 10.48 & 21.02 \\
\hline 10 & [Ca(4- Aaнo- $1 \mathrm{nr})]$ & 13.1 & $(49.73)$ & $(4.24)$ & $(10.62)$ & $(21.22)$ \\
\hline
\end{tabular}

\section{Nuclear Magnetic Resonance Spectra $\left({ }^{1}\right.$ H-NMR)}

5- طيف الرنين النووي المغناطيسي :

قُيسِتْ أطياف الرنين النووي المغناطيسي لليكاندين (L2)\& (L1), باستخدام مذيب (DMSO-d ) والمرجع القياسي وتم تفسير الطيف تبعا لقيم الإشارات الكيميائية التي ظَهرت , اعطى طيف الرنين النووي المغناطيسي إثارة عريضة

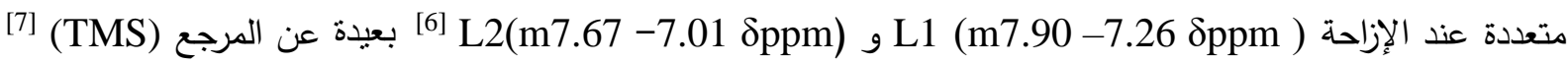
التي تدل على مجموعة بروتونات الحلقات الاورماتية لليكاند الأول والثاني على التوالي, وظهور أشارة البروتون العائد لمجموعة 
الليكاند الاول والثاني على (s $9.54 \delta$ ppm) (s 9.45 \& ppm) (عند الازاحة الكيمياوية (التوالي [8]وبروتون الكحولي للحامض الاميني السيرين (s 6.65 Sppm) اما فيما يخص الليكاند الثاني ظهرت الازاحة الكيمياوية للبروتون الكحولي للحامض الاميني الثريونين عند (s 6.78 Sppm) وظهور حزم مجاميع المثيل لكلا الليكاندين قرب المرجع (TMS) والجدولين (4-3) تبينَ أهم الإزاحات الكيمياوية في طيف الرنين النووي المغناطيسي لكل من

K4-AdHb -Ser الإزاحة الكيمياوية لليكاند الأول(ppm )

$(7.90-7.26$ Sppm $)(\mathrm{m}, 8 \mathrm{H})$ phenyl

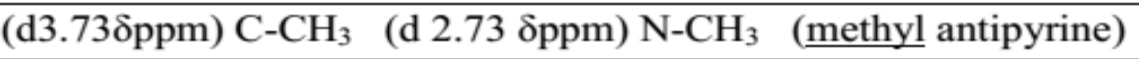

(s $9.45 \delta \mathrm{ppm}$ ) Azomethine proton $-\underline{\mathrm{HC}}=\mathrm{N}$

( s 2.80 8ppm ) (1H N -

(2.49-3.12 $\delta \mathrm{ppm})$ singlet, ( $\underline{\mathrm{H}}$ for DMSO protons $\delta \mathrm{ppm})$

$\mathrm{OH}$ at ( s $8.14 \delta \mathrm{ppm})-$ phenolic

(d $3.6 \delta \mathrm{ppm})-\underline{\mathrm{CH}}-\mathrm{OH}$ for srrine group

(s $6.65 \delta \mathrm{ppm}) \mathrm{s} 1 \mathrm{H}$ for $-\underline{\mathrm{OH}} \mathrm{Hydroxyl}$ group of serine

الجدول (4) يبين أهم الإزاحات الكيمياوية في طيف الرنين النووي المغناطيسي (1)

K ${ }_{4}$-AdHb-Thr الإزاحة الكيمياوية لليكاند الثاني(ppm )

$(7.76-7.01 \quad \delta p p m)(\mathrm{m}, 8 \mathrm{H}$,$) phenyl$

(3.78סppm) dC- $\mathrm{CH}_{3} \quad(2.73 \delta \mathrm{ppm}) \mathrm{N}-\mathrm{CH}_{3}$ (methyl antipyrine)

(s $9.54 \delta \mathrm{ppm})$ Azomethine proton $-\underline{\mathrm{HC}}=\mathrm{N}$

(1.04 $\delta \mathrm{ppm})$ ( t 1H - $\underline{\mathrm{CH}}-\mathrm{COO}-)$

(3.33 -2.49 $\delta \mathrm{ppm}$ ) singlet, ( $\underline{6 \mathrm{H}}$ for DMSO protons $\delta \mathrm{ppm})$

( d $2.40 \delta p p m) \mathrm{CH}-\mathrm{CH}_{3}$ for Thrionine

$\mathrm{OH}$ at ( s $9.22 \delta \mathrm{ppm})-$ Phenolic

(q $2.08 \delta \mathrm{ppm})-\mathrm{CH}-\mathrm{OH}$ for Therionine group

(s $6.78 \delta \mathrm{ppm})$ s $1 \mathrm{H}$ for $-\mathrm{OH}$ Hydroxyl group of Therionine 


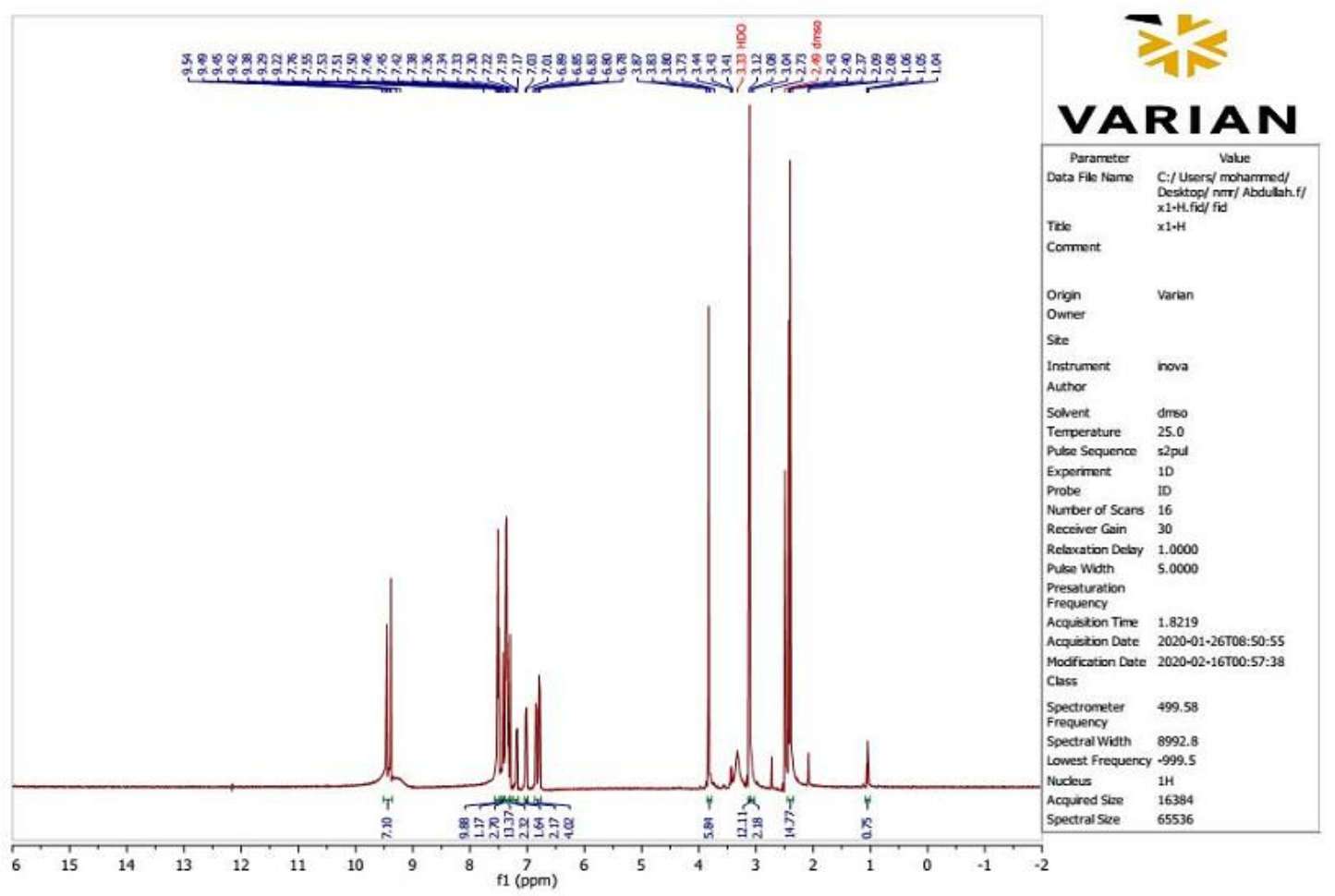

طيف الرنين النووي المغناطيسي اللبرونون

Infrared Spectra

6- أطياف الأشعة تحت الحمراء:

أظهرت قياسات الأشعة تحت الحمراء لليكاندين ( L1 ) و ( L2 ) ) التردد الامتطاطي لمجموعة الازوميثاين(C=N) (1582 - $\left.1583 \mathrm{~cm}^{-1}\right)$ (N) مع الفلز وتعود إزاحتها نحو تردد اوطاة بسبب الضعف الذي يحدث في خاصية الآصرة المزدوجة لمجموعة (C=N) وهذا يتفق مع ما نشر في الأدبيات والبحوث [9], كذلك لؤحظظ ظُهور حزمة عريضة في المنطقة الممتدة مابين (3200 Cm-1300) وفي دراستتاً ظَهرتْ هذه الحزم

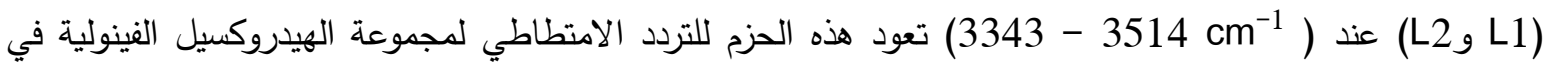

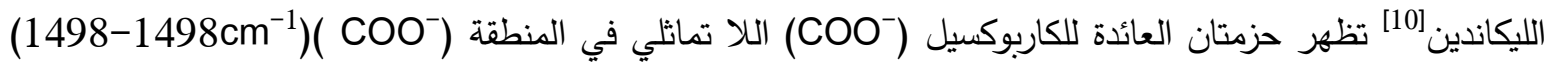
والتماثلي في المنطقة (1373-148m-1378) لليكاندات الاول والثاني على التوالي, ويعد الفرق في التردد التماثلي واللاتماثلي تثخيصا لسلوك مجموعة الكاربوكسيل فعند الارتباط مجموعة (COO') بالايون الفلزي بشكل ثنائي السن يكون الفرق في التردد اقل من (120 cm 120 بينما عند ارتباط هذه المجموعة بثكل أحادي السن مع الايون الفلزي تزاح حزمة التماتلي لمجموعة (COO') نحو التردد الأوطأ وحزمة (COO) اللاتماثلي تزاح نحو تردد أعلى ويكون الفرق أعلى من

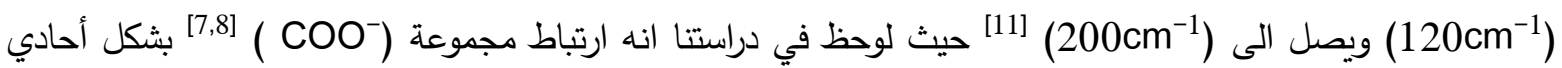
السن و تردد الامتطاطي اللاتماثلي يزداد (1511 cm-151-1507) بينما التردد التماثلي يقل (1366 cm-1-1323) يؤكد هذا التتاسق مع الايون الفلزي,بشكل أحادي السن, وكذلك ظُهور حزم عائده (M-O) [6] عند تردد ظهور 584- 573 


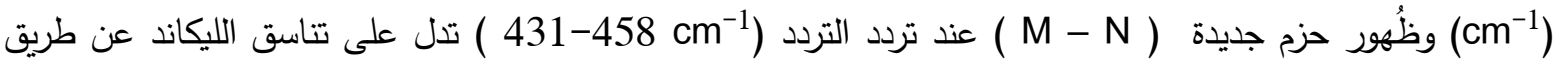

$$
\begin{aligned}
& \text { ذرت النتروجين [12] مع الايون الفلزي والجدول (5) يُبيَن أهم الحزم لليكاندين ومعقداتهما. }
\end{aligned}
$$

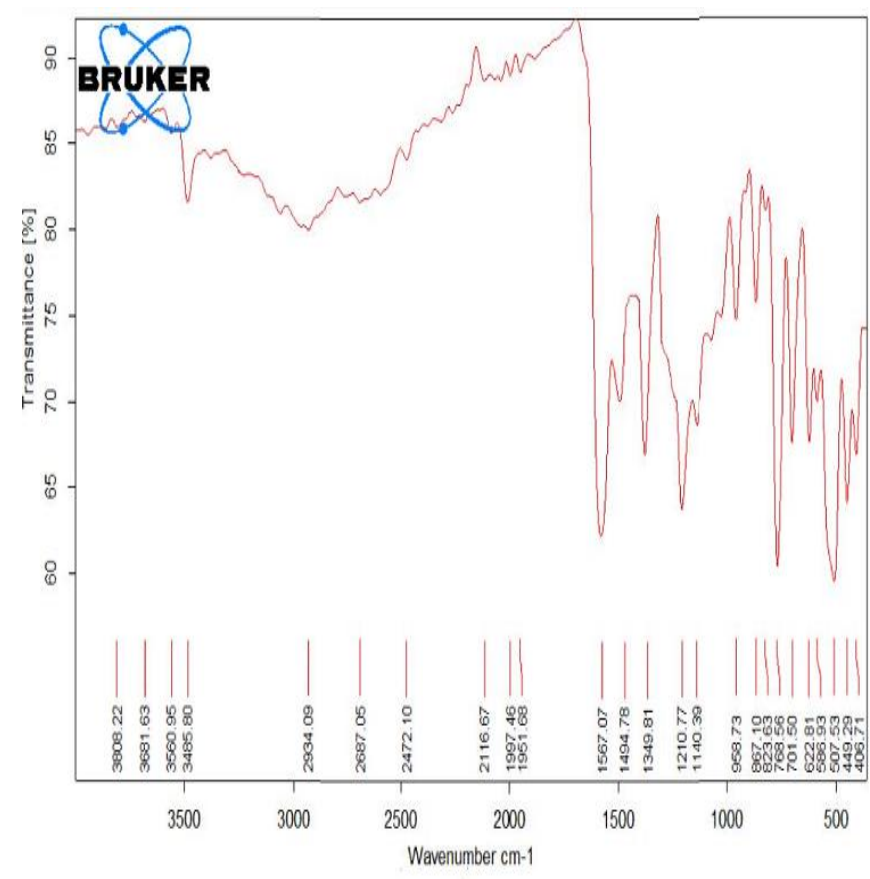

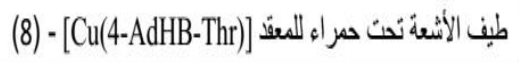

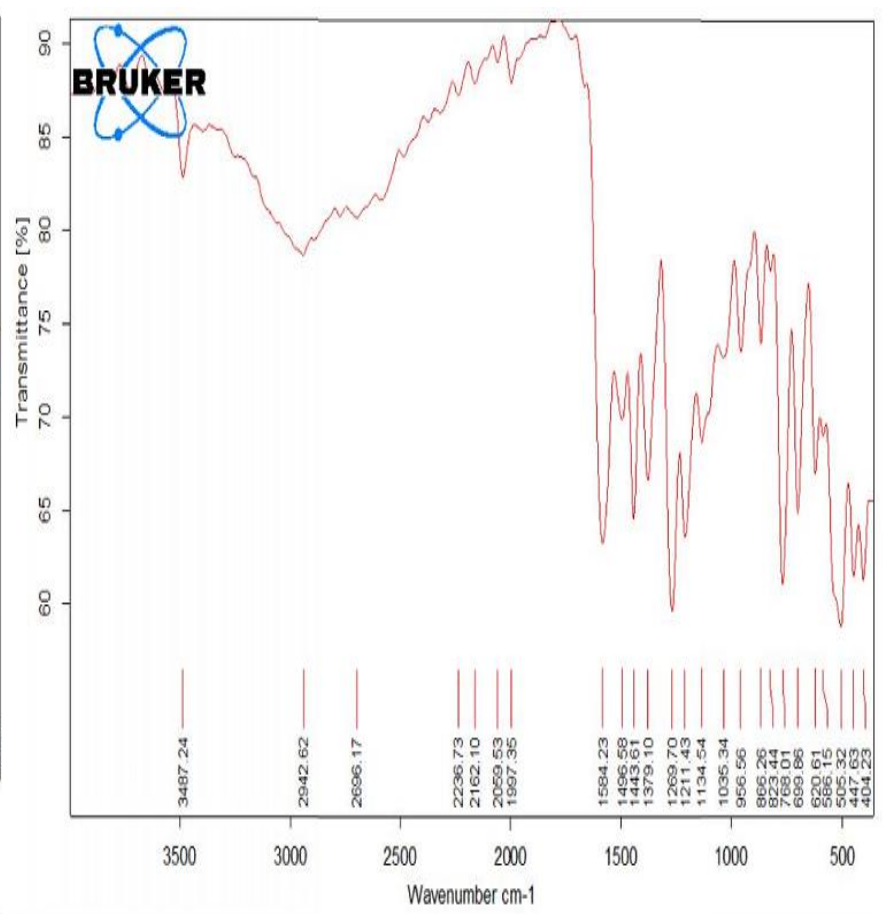

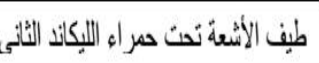


جدول(5): قيم الترددات للحزم الفعالة في طيف الأثشعة تحت الحمراء لليكاندان ومعقداتهما المحضرة

\begin{tabular}{|c|c|c|c|c|c|c|c|c|}
\hline Comp. & $\begin{array}{l}v(0- \\
\text { H)ph }\end{array}$ & $v(C=N)$ & $v(C-O)$ & $\begin{array}{l}\text { vasmy } \\
\text { (COO-) }\end{array}$ & $\begin{array}{c}\text { vsmy } \\
(\mathrm{COO}-)\end{array}$ & $v(M-N)$ & $v(M-O)$ & Others \\
\hline L1 & 3487 & 1582 & 1267 & 1498 & 1443 & -- & -- & $\begin{array}{c}\text { Alph-v (C-H ) } 2926 \\
\text { Ar-v(C-H ) } 3006 \\
\end{array}$ \\
\hline 1. & $\begin{array}{l}3389 \\
3196 \\
\end{array}$ & 1579 & 1236 & 1510 & 1323 & 431 & 584 & $\begin{array}{l}\text { Alph-v (C-H )2934 } \\
\text { Ar-v(C-H ) } 3097\end{array}$ \\
\hline 2. & $\begin{array}{l}3343 \\
3192 \\
\end{array}$ & 1567 & 1233 & 1511 & 1338 & 443 & 579 & $\begin{array}{l}\text { Alph-v (C-H )2922 } \\
\text { Ar-v(C-H }) 3092 \\
\end{array}$ \\
\hline 3. & $\begin{array}{l}3376 \\
3166 \\
\end{array}$ & 1566 & 1227 & 1516 & 1332 & 458 & 580 & $\begin{array}{l}\text { Alph-v (C-H )2946 } \\
\text { Ar-v(C-H ) } 3014\end{array}$ \\
\hline 4. & $\begin{array}{l}3381 \\
3177 \\
\end{array}$ & 1574 & 1225 & 1508 & 1341 & 438 & 577 & $\begin{array}{c}\text { Alph-v (C-H )2967 } \\
\text { Ar-v(C-H ) } 3011 \\
\end{array}$ \\
\hline 5. & $\begin{array}{l}3374 \\
3196 \\
\end{array}$ & 1563 & 1243 & 1507 & 1346 & 443 & 578 & $\begin{array}{l}\text { Alph-v (C-H )2931 } \\
\text { Ar-v(C-H ) } 3032 \\
\end{array}$ \\
\hline L2 & 3490 & 1583 & 1268 & 1498 & 1378 & -- & - & $\begin{array}{c}\text { Alph-v (C-H ) } 2943 \\
\text { Ar-v(C-H ) } 3010 \\
\end{array}$ \\
\hline 6. & $\begin{array}{l}3508 \\
3202 \\
\end{array}$ & 1566 & 1218 & 1507 & 1366 & 438 & 575 & $\begin{array}{c}\text { Alph-v (C-H )2941 } \\
\text { Ar-v(C-H ) } 3010\end{array}$ \\
\hline 7. & $\begin{array}{l}3507 \\
3222 \\
\end{array}$ & 1561 & 1222 & 1504 & 1361 & 441 & 573 & $\begin{array}{l}\text { Alph-v (C-H )2971 } \\
\text { Ar-v(C-H ) } 3019 \\
\end{array}$ \\
\hline 8. & $\begin{array}{l}3508 \\
3211 \\
\end{array}$ & 1563 & 1226 & 1505 & 1361 & 447 & 577 & $\begin{array}{l}\text { Alph-v (C-H ) } 2948 \\
\text { Ar-v(C-H ) } 3032\end{array}$ \\
\hline 9. & $\begin{array}{l}3503 \\
3235 \\
\end{array}$ & 1569 & 1228 & 1513 & 1365 & 446 & 579 & $\begin{array}{l}\text { Alph-v (C-H )2965 } \\
\text { Ar-v(C-H ) } 3021\end{array}$ \\
\hline 10. & $\begin{array}{l}3514 \\
3214 \\
\end{array}$ & 1560 & 1221 & 1510 & 1364 & 453 & 573 & $\begin{array}{l}\text { Alph-v (C-H )2955 } \\
\text { Ar-v(C-H ) } 3007 \\
\end{array}$ \\
\hline
\end{tabular}

7- الأطياف الاكترونية والقياسات المغناطيسية : Electronic Spectroscopy and Magnetic Measurements

قيست الأطياف الاككترونية للمعقدات المحضرة في دراستنا باستخدام مذيب ثنائي مثيل فورماميد (DMF) وعند تركيز 30-30) وباستخدام خليتين كوارتز ذواتي قطر (1cm) وقد أعطت المعقدات المضرة أطياف (d-d) فضلاً عن أطياف انتقال الثحنة (C.T) أن معقدات الكوبلت (II) المحضرة (1,6) فقد وجد عملياً أن قيمة العزم المغناطيسي هي (2.51 B.M) 2.68) وهذا يتقق مع قيم العزم المغناطيسي لمعقدات الكوبلت (II) واطئ البرم ذات بنية المربع المستوي [13] اذ أظهرت نتائج قياسات الطيف الاككتروني لمعقدات الكوبلت (1,6) حزم امتصاص في المنطقة (18484 cm-18761-18) والتي تعود للانتقال (20g) (2,7) فقد أظهرت خواص دايامغناطيسية مما يدل على أن هذه المعقدات تتخذ شكل مربع مستوي[15]، أذ اظهرت معقدات النيكل المحضرة (2,7) في الطيف الاككتروني حزم امتصاص عند (19920 cm-1 (19220) وهي تعود للانتقال

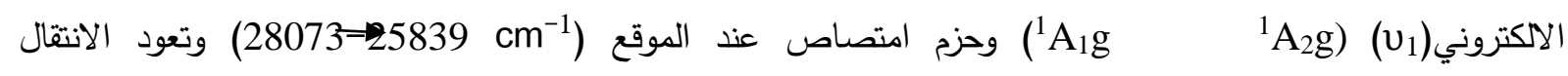

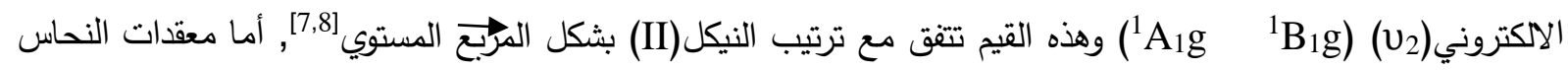
المحضرة (3,8 فقد أظهرت القياسات المغناطيسية لها عزماً مغناطيساً(1.82-1.88 B.M) وهذه القيم تثير إلى تركيب 
رباعي التناسق ذات الثكل المربع المستوي حول ايون النحاس(II)]16] ، اذ أظهرت في الطيف الآكتروني حزم امتصاص

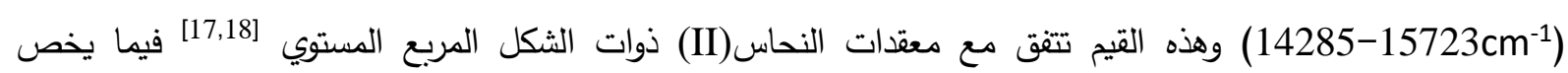
معقدات(Cd, Zn) المحضرة (4,5,9,10) دايامغناطيسية لامتلاكها أوربتالات (d) الممتئة بالأكترونات[19] وتم قياس

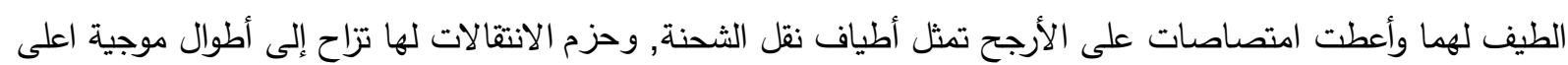
او اوطى", من أطياف الليكاندات مشيرة بذلك إلى تكوين المعقدات [20] الجدول (6) يُبيين القياسات المغناطيسية والأطياف

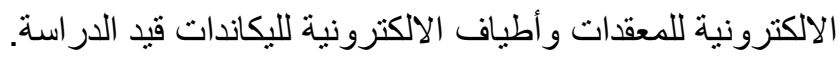

الجدول (6) يبين أهم حزم الانتقالات الاككترونية لليكاند (L L1) المحضرة ومعقداتهما مع نتائج القياسات

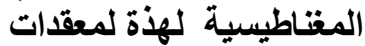

\begin{tabular}{|c|c|c|c|c|c|}
\hline No & Compound & $\mu \mathrm{eff}$ (B.M) & Assignment & $\begin{array}{r}\text { Band maxima } \\
\lambda\left(\mathrm{cm}^{-1}\right)\end{array}$ & Strut \\
\hline $\mathbf{L}_{1}$ & $\underset{5}{\mathrm{C}_{21} \mathrm{H}_{21} \mathrm{KN}_{4} \mathrm{O}}$ & --- & $\mathrm{n} \rightarrow \pi^{*}, \pi \rightarrow \pi^{*}$ & 28089 ،30674 & --- \\
\hline 1 & $\mathrm{~L}_{1} \mathrm{Co}$ & 2.68 & ${ }^{2} A_{1} g \rightarrow{ }^{2} E^{\prime} g \quad, C-T$ & 18484,32894 & S.q \\
\hline 2 & $\mathbf{L}_{1} \mathbf{N i}$ & Diamagnetic & $\begin{aligned}{ }^{1} \mathrm{~A}_{1} \mathrm{~g} & \rightarrow{ }^{1} \mathrm{~A}_{2} \mathrm{~g} \\
{ }^{1} \mathrm{~A}_{1} \mathrm{~g} & \rightarrow{ }^{1} \mathrm{~B}_{1} \mathrm{~g}, \mathrm{C}-\mathrm{T}\end{aligned}$ & 19920,25839 & S.q \\
\hline 3 & $\mathbf{L}_{1} \mathbf{C u}$ & 1.82 & $\begin{array}{l}{ }^{2} \mathrm{~B}_{1} \mathrm{~g} \rightarrow{ }^{2} \mathrm{~A}_{1} \mathrm{~g}, \\
{ }^{2} \mathrm{~B}_{1} \mathrm{~g} \rightarrow{ }^{2} \mathrm{Eg}, \quad \mathrm{C}-\mathrm{T}\end{array}$ & $\begin{array}{c}15723,20120 \\
33112\end{array}$ & S.q \\
\hline 4 & $\mathbf{L}_{1} \mathbf{Z n}$ & Diamagnetic & C-T & 26315,33898 & Tet \\
\hline 5 & $\mathbf{L}_{1} \mathbf{C d}$ & Diamagnetic & C-T & 24691,35842 & Tet \\
\hline $\mathbf{L}^{2}$ & $\mathrm{C}_{22} \mathrm{H}_{23} \mathrm{KN}_{5} \mathrm{O}$ & ----- & $\mathrm{n} \rightarrow \pi^{*} \quad, \quad \pi \rightarrow \pi^{*}$ & 26954,32258 & --- \\
\hline 6 & $\mathbf{L}^{2} \mathrm{Co}$ & 2.51 & ${ }^{2} \mathrm{~A}_{1} \mathrm{~g} \rightarrow{ }^{2} \mathrm{Eg}, \mathrm{C}-\mathrm{T}$ & 18761,32258 & $\mathrm{Sq}$ \\
\hline 7 & $\mathbf{L}^{2} \mathrm{Ni}$ & Diamagnetic & $\begin{array}{l}{ }^{1} \mathrm{~A}_{1} \mathrm{~g} \rightarrow{ }^{1} \mathrm{~A}_{2} \mathrm{~g} \\
{ }^{1} \mathrm{~A}_{1} \mathrm{~g} \rightarrow{ }^{1} \mathrm{~B}_{1} \mathrm{~g}, \mathrm{C}-\mathrm{T}\end{array}$ & $\begin{array}{c}19220 \\
28073,32679\end{array}$ & $\mathrm{Sq}$ \\
\hline 8 & $\mathbf{L}^{2} \mathbf{C u}$ & 1.88 & $\begin{array}{l}{ }^{2} \mathrm{~B}_{1} \mathrm{~g} \rightarrow{ }^{2} \mathrm{~A}_{1} \mathrm{~g}, \\
{ }^{2} \mathrm{~B}_{1} \mathrm{~g} \rightarrow{ }^{2} \mathrm{Eg}, \mathrm{C}-\mathrm{T}\end{array}$ & $\begin{array}{c}14285,24814 \\
33211\end{array}$ & S.q \\
\hline 9 & $\mathbf{L}^{2} \mathbf{Z n}$ & Diamagnetic & C.T & 26453,33672 & Tet \\
\hline 10 & $\mathbf{L}^{2} \mathbf{C d}$ & Diamagnetic & C.T & 26737,38461 & Tet \\
\hline
\end{tabular}



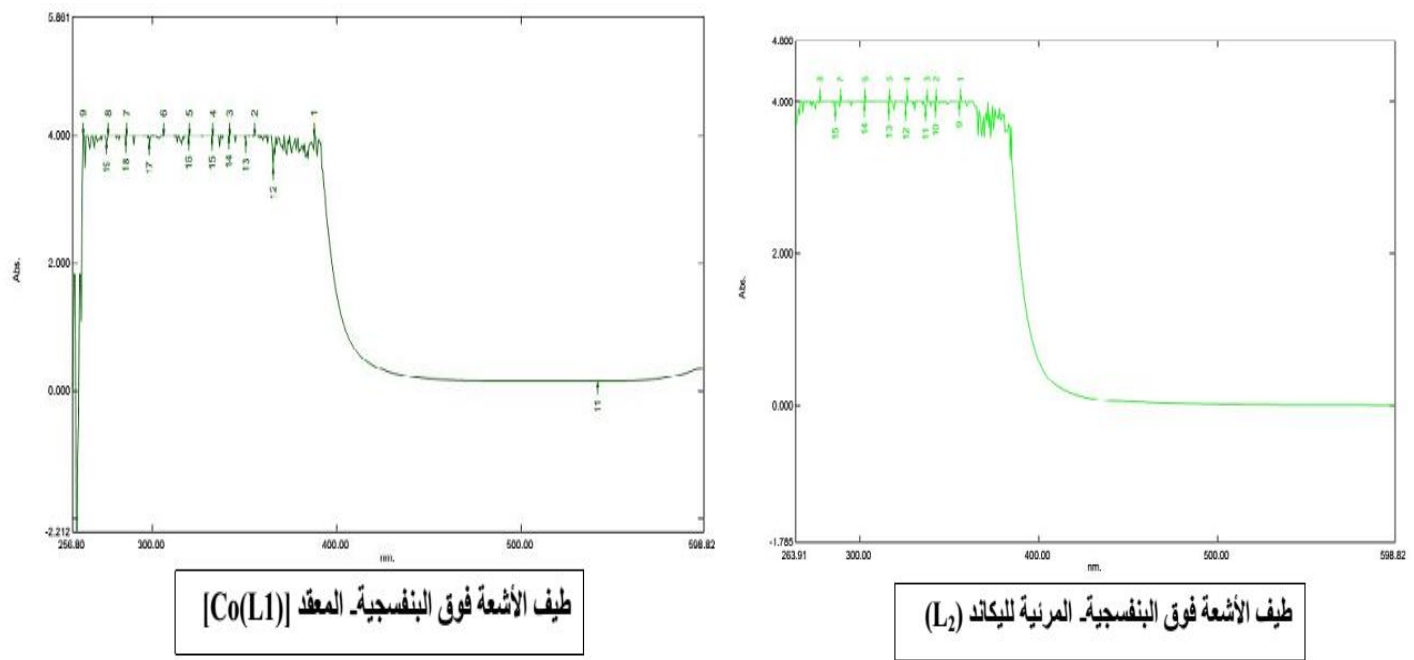

Thermal Analysis

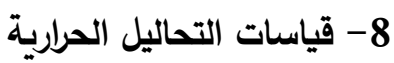

تمر عملية التحلل الحراري لكل من معقد الكوبلت مع الليكاند الاول ومعقد النيكل مع الليكاند الثاني بخمس مراحل ولؤحظ الاستقرار الحراري الجيد وتُبين أن المعقدات لا تتأثر بالهواء والرطوبة وهذا يدل على الثبوّت الحراري والنقاوة العاليتين وإضافة لذلك درجة الانصهار العالية التي تُعطي دليلاً على الاستقرارية العالية للمعقدات المحضرة [21]حيث تمت لت دراسة التحلل الحراري ألوزني (TG) والتحلل الحراري التفاضلي (DTG) والتحلل الحراري ألمسعري (DSC) وقيست النماذج بدرجات حرارية عند مدى الجهاز (28-600C) اظهر منحني (TG) للمعقد ذو الصيغة الوضعية تفكك المعقد [ (Co(L $\left.\mathrm{C}_{21} \mathrm{H}_{20} \mathrm{CoN}_{4} \mathrm{O}_{5}\right)$

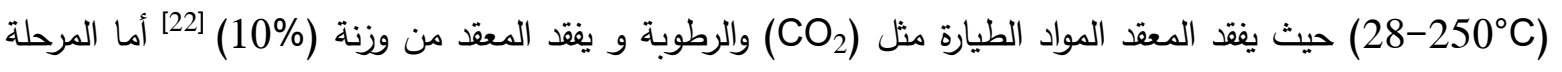
الثانية تقع عند المدى (250-400C) يحصل فقدان لمجاميع الازوميثين(C=N-) على شكل غاز حيث يفقد المعقد من وزنه (30\%) [23] ,أما المرحلة الثالثة عند المدى(500C- (400) يفقد المعقد من وزنه (50\%) حيث يتم فقدان مجاميع المثيل والمثيلين (-OH) $\left(\mathrm{CH}_{2}-, \mathrm{CH}_{3}{ }^{-}\right)$للحامض الاميني والمجاميع المعوض على حلقة البيرازول, أما المرحلة الرابعة فتكون ضمن المدى (580C-56 (2, $\mathrm{C}_{6} \mathrm{H}_{5}$ الجزء المتبقي من الليكاند عند درجة حرارة (600C) اي فقدان لحلقة الانتي بايرين وماتبقى من الليكاند وتصل نسبة الوزن المفقود الى (88\%) وعند درجة حرارة (600C) حيث يتفكك المعقد كليا ويتبقى فقط ذرات الفلز بشكل اوكسيد فلزي][25] , وناتج عملية الاحتراق كاربون (فحم) ويرافقه قم ماصة للحرارة في منحني (DSC) وهذا ينطبق على المعقد الثاني قيد الدراسة. 
الجدول (7) يبين نتائج قياس التحاليل الحرارية(TGA,DTG,DSC) للمعقدين رقم(1) ورقم (7).

\begin{tabular}{|c|c|c|c|c|c|c|}
\hline Complexes & $\begin{array}{c}\text { TG } \\
\text { Range } \\
\left({ }^{\circ} \mathrm{C}\right)\end{array}$ & $\begin{array}{l}\text { DTG } \\
\text { Max } \\
\left({ }^{\circ} \mathrm{C}\right)\end{array}$ & $\begin{array}{l}\text { Mass } \\
\% \text { loss }\end{array}$ & Assignment & Residue & $\begin{array}{l}\text { DSC } \\
\left({ }^{\circ} \mathrm{C}\right)\end{array}$ \\
\hline \multirow{5}{*}{$1-\left[\mathrm{C}_{21} \mathrm{H}_{20} \mathrm{CoN}_{4} \mathrm{O}_{5}\right]$} & $28-250$ & \multirow[t]{2}{*}{255} & 10 & Evolution of $\mathrm{CO}_{2} \&$ moisture & \multirow[b]{5}{*}{$\mathrm{CoO}+2 \mathrm{C}$} & \multirow{5}{*}{$\begin{array}{c}250(+) \\
330(+) \\
500(+) \\
530(+)\end{array}$} \\
\hline & $250-400$ & & 30 & -Loss Azomethine groups & & \\
\hline & $400-500$ & \multirow{3}{*}{$\begin{array}{l}310 \\
320 \\
330 \\
360\end{array}$} & 50 & $\begin{array}{c}\text { LossCH}_{3} \text { group of amino acid } \\
\text { and part of pyrazole } \\
\text {-Loss OH group }\end{array}$ & & \\
\hline & $500-580$ & & 70 & $\begin{array}{c}\text {-Loss phenyl Ring } \\
\text { And some a part of the ligand } \\
\text { and pyrazole Ring }\end{array}$ & & \\
\hline & 600 & & 88 & Lose all part of the ligand & & \\
\hline \multirow{5}{*}{ 7- $\left[\mathrm{C}_{22} \mathrm{H}_{22} \mathrm{~N}_{4} \mathrm{NiO}_{5}\right]$} & $27-270$ & \multirow{5}{*}{$\begin{array}{l}200 \\
280 \\
300 \\
340 \\
360 \\
550\end{array}$} & 10 & Evolution of $\mathrm{CO}_{2} \&$ moisture & \multirow[b]{5}{*}{$\mathrm{NiO}+2 \mathrm{C}$} & \multirow{5}{*}{$\begin{array}{l}260(+) \\
420(+) \\
550(+)\end{array}$} \\
\hline & $270-300$ & & 25 & -Loss Azomethine groups & & \\
\hline & $\begin{array}{l}300-400 \\
400-450\end{array}$ & & $\begin{array}{l}40 \\
45\end{array}$ & $\begin{array}{c}\text { - } \text { LossCH}_{3} \text { group of amino acid } \\
\text { and part of pyrazole } \\
\text {-Loss OH group }\end{array}$ & & \\
\hline & $450-500$ & & 65 & $\begin{array}{c}\text {-Loss phenyl Ring } \\
\text { And some a part of the ligand } \\
\text { and pyrazole Ring }\end{array}$ & & \\
\hline & $\begin{array}{c}500-570 \\
600\end{array}$ & & 85 & Lose all part of the ligand & & \\
\hline
\end{tabular}



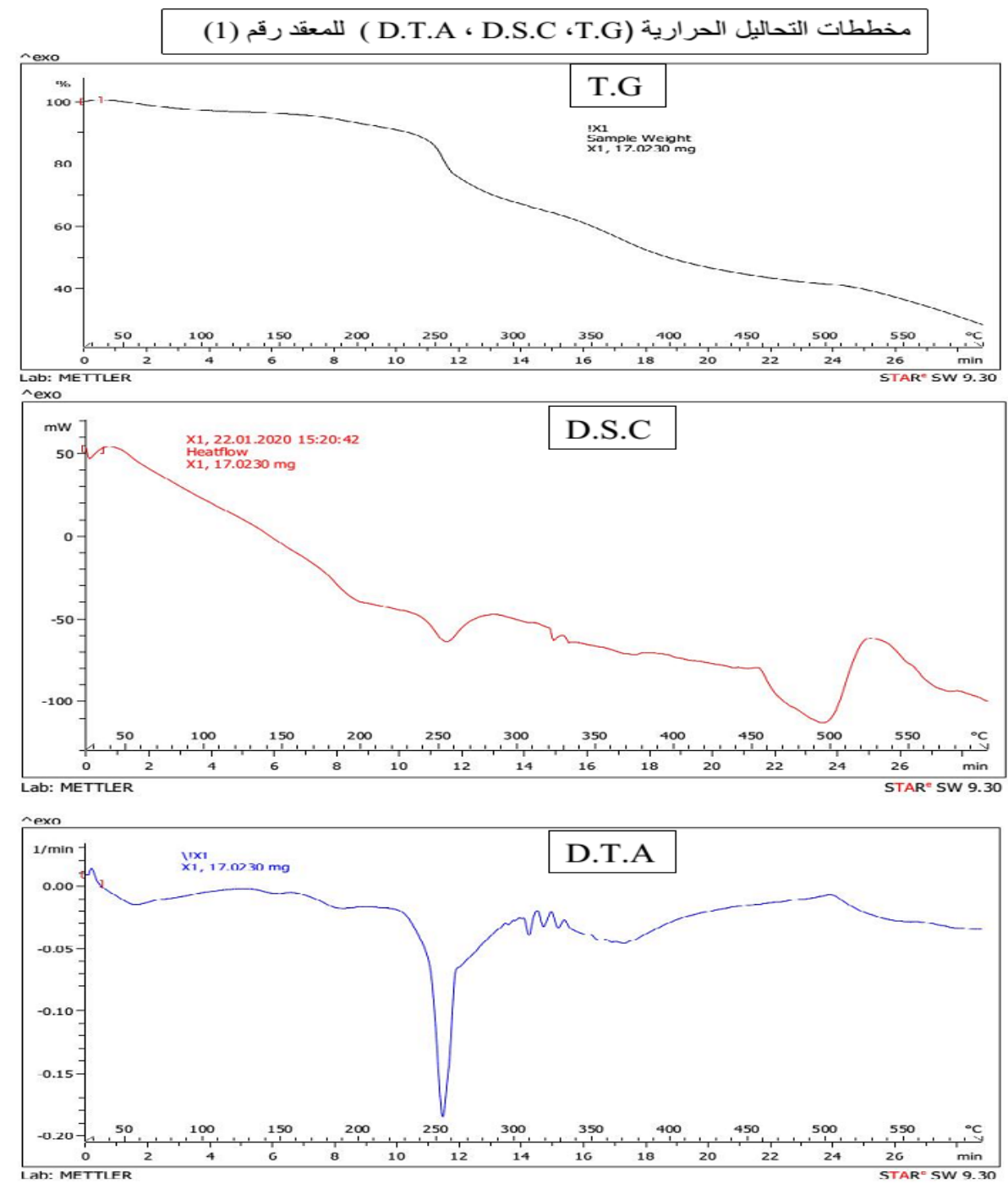

9- حيود الأشعة السينية للمسحوق XRD study : أن قياس حيود الأشعة السينية لمعقد رقم (2) النيكل مع الليكاند 1أذ ان تحليل بيانات النموذج التي تم الحصول باستعمال برنامج (X’perthigh score software package) أذ إن المنطقة مابين (90-10² تدل على وجود حزم(قم) تشخيصية حادة في المخطط وتدل هذه القهم على الحالة البلورية لمعقد الكوبلت تدل وجود شكل بلوري حاوي على مستويات بلورية وتراكيب شبكية. ولتفسير النتائج (crystalline nature) تم الاستعانة بقانون براغ Bragg’s law لغرض حساب التباعد بين المستويات البلورية المختلفة (d-spacing) تمثل وجل

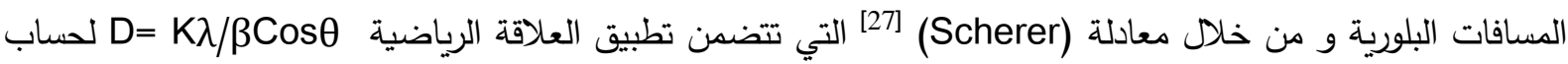
الحجم البلوري للمعقد (2) وذلك نظرا لوجود مستوى بلوري وشبكة بلورية crystalline- nature ـ استخدمت معادلة ديباي - شرر Scherer Debye والمخططات الآتية تظُهر نتائج تحليل بيانات قياس حُيود الأشعة السينية للمعقد رقم .[X'perthigh score software package], باستعمال برنامج,(2) 


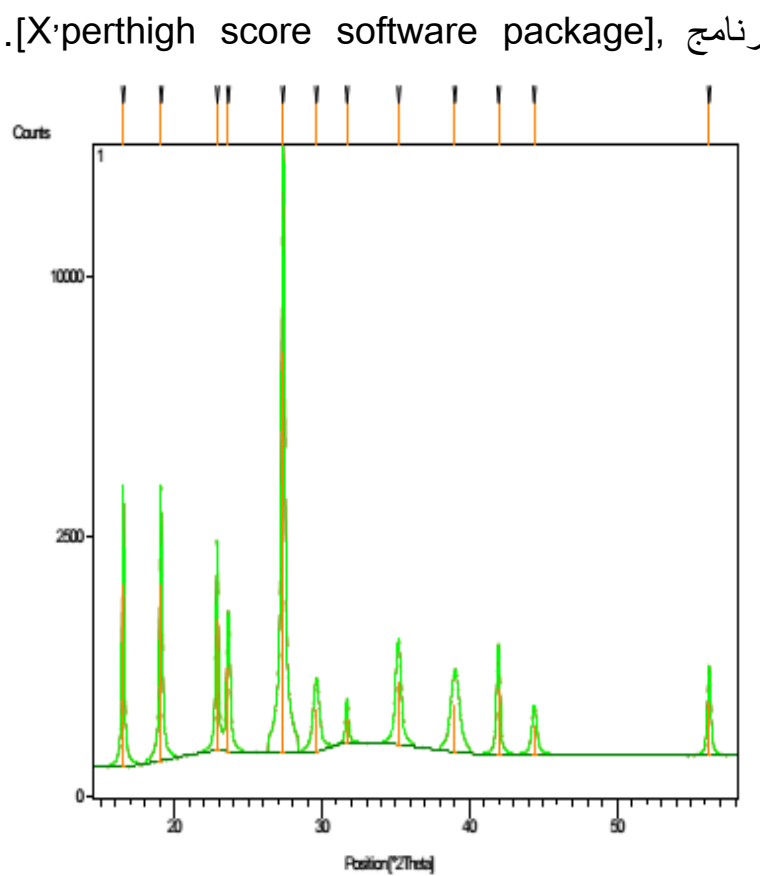

نتائج تحليل البيانات البلورية للمعقد رقم (2) بال

\begin{tabular}{rrrrr}
\hline $\begin{array}{r}\text { Pos. } \\
\text { [ } 2 \text { Th.] }\end{array}$ & $\begin{array}{r}\text { Height } \\
\text { [cts] }\end{array}$ & $\begin{array}{r}\text { FWHM } \\
{\left[{ }^{\circ} 2 \text { Th.] }\right.}\end{array}$ & d-spacing & $\begin{array}{l}\text { Rel. Int. } \\
{[\%]}\end{array}$ \\
\hline 16.5298 & 1626.79 & 0.1476 & 5.36306 & 22.67 \\
19.0761 & 1627.70 & 0.1968 & 4.65253 & 22.68 \\
22.8728 & 1065.20 & 0.1968 & 3.88813 & 14.84 \\
23.6436 & 545.97 & 0.2952 & 3.76309 & 7.61 \\
27.3469 & 7176.77 & 0.2460 & 3.26132 & 100.00 \\
29.5977 & 202.18 & 0.5904 & 3.01824 & 2.82 \\
31.6760 & 112.80 & 0.2952 & 2.82479 & 1.57 \\
35.2048 & 372.58 & 0.4920 & 2.54931 & 5.19 \\
39.0444 & 241.00 & 0.7872 & 2.30701 & 3.36 \\
41.9692 & 365.14 & 0.2952 & 2.15275 & 5.09 \\
44.4013 & 113.42 & 0.4920 & 2.04032 & 1.58 \\
56.2371 & 262.01 & 0.3000 & 1.63442 & 3.65 \\
\hline
\end{tabular}

\begin{tabular}{|c|c|}
\hline Crystallite Size D(nm) & Lattice Strain \\
\hline 39.08 & 0.0066 \\
\hline 38.29 & 0.0057 \\
\hline 37.37 & 0.0049 \\
\hline 32.37 & 0.0055 \\
\hline 26.88 & 0.0057 \\
\hline 27.80 & 0.0051 \\
\hline 27.13 & 0.0044 \\
\hline 34.05 & 0.0032 \\
\hline 41.23 & 0.0025 \\
\hline 29.58 & 0.0034 \\
\hline 28.16 & 0.0033 \\
\hline 28.54 & 0.0027 \\
\hline
\end{tabular}

\section{NOT REFINED UNIT CELL}

h $\mathrm{k} 1$ SST-OBS SST-CALC DELTA 2TH-OBS 2TH-CALC D-OBS

$\begin{array}{llllllllll}0 & 0 & 1 & 020630 & 020630 & 000000 & 16.516 & 16.516 & 5.3630\end{array}$

$\begin{array}{lllllllllllll}0 & 1 & 2 & 2 & .027383 & 027383 & 000000 & 19.050 & 19.050 & 4.6550\end{array}$

$\begin{array}{llllllllllll}0 & 1 & 1 & 1 & 039262 & 039262 & 000000 & 22.857 & 22.857 & 3.8875\end{array}$

$\begin{array}{lllllllllll}1 & 0 & 2.055816 & 055816 & 000000 & 27.331 & 27.331 & 3.2605\end{array}$

$\begin{array}{llllllllllll}1 & 0 & 1 & 091274.091274 & 000000 & 35.169 & 35.169 & 2.5497\end{array}$

$\begin{array}{llllllllll}1 & 1 & 1 & 1 & 111256 & 111256 & 000000 & 38.969 & 38.969 & 2.3094\end{array}$

Triclinic system with a =3.457607 $\quad b=4.900937 \mathrm{c}=11.632220 \longrightarrow[\mathrm{Ni}(\mathrm{L} 1)]$
$\begin{array}{lll}\text { ALFA }=55.050740 \text { BETA }=120.497000 & \text { GAMMA }=75.090450 & \alpha \neq \beta \neq \gamma \neq 90 \\ \text { UNIT CELL VOLUME }=139.06 \times 10^{-3} \mathrm{~A}^{\circ} \quad \mathrm{Z}=2 & \text { group space }=\mathrm{P} 1\end{array}$ 


\section{Bacterial activates}

10 - الفعالية البكتيرية للمركبات المحضرة:

تم إجراء الفعالية البيولوجية لليكندات المحضرة وبعض معقداتها الفلزية قيد الدراسة, حيث تضمنت هذه الدراسة تطبيق الفعالية البيولوجية على بعض أنواع البكتريا المشخصة مختبريا باستخدام الاختبارات الكيميوحياتية والمجهرية وتعد هذه البكتريا المعزولة التي تسبب كثيرمن الامراض للانسان .حيث تضمنت الدراسة لأربعة أنواع من البكتريا منها بكتريا

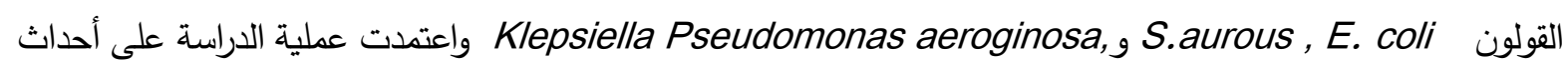
ثقوب في الوسط الزراعي داخل الطبق بواسطة الثاقب الفيليني المعقم بالايثانول المركز ثم يتم إجراء المسح للبكتريا بواسطة

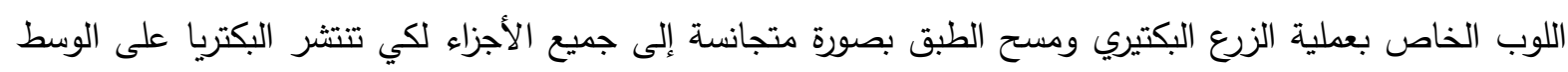
الزراعي (Mueller Hinton ager) بصورة كاملة وبعد ذلك يتم وضع المحاليل المحضرة في دراستنا بتركيز

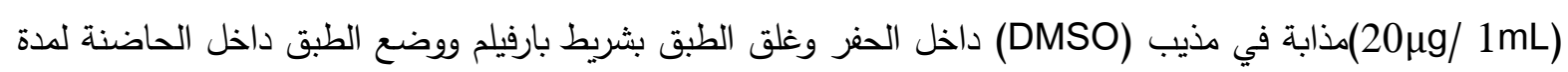
24 ساعة في درجة حرارة 37 مئوية. بعد تم قياس قطر التثبيط باستخدام طريقة [29] بالمسطرة و أظهرت المركبات المحضرة في مدرستتا فعالية جيدة جدا وقسم من المركبات أظهرت فعالية اعلي من المواد القياسية (Amoxicillin) ولتفسير الفعالية الحيوية للمعقدات الفلزية المحضرة في دراستتا على أساس النظرية المخلبية و مفهوم التغلب على وفقا النفاية الخلية (الغثاء ألدهني ) الذي يحيط بالخلية والذي يفضل مرور المواد الذائب دهينا فقط لان النظام ألدهني مهم في السيطرة على النشاط المضاد للأحياء المجهرية فان العامل المخلبي وفقا لقطبية الايون الفلزي تقلل لدرجة كبيرة بسبب التداخل الاوربيتالي للكل من اوربيتالات الليكاند والايون[30] الفلزي والمشاركة الجزئية للشحنة بين الأيون الموجب والذرات المانحة والأكثر أنها تزيد من انتشار الاككترونات على الحلقة المخلبية وتعزز الألفة الدهنية للمعقد وهذه الزيادة في الألفة تودي الى كسر حاجز النفاذية للخلية وبالتالي تاخير عمليات الأيض الخلوي الطبيعي [31] الجدول (11) يبين درجة التثبيط في البكتريا باستخدام لليكاندين ومعقداتهما المحضرة قيد الدراسة . 
Journal of Education and Science (ISSN 1812-125X), Vol: 29, No: 4, 2020 (42-61)

الجدول (8) يبين الفعالية (مساحة التثبط البكتيري بالمليمتر) لليكاندات وبعض معقداتها المحضرة.

\begin{tabular}{||c|c|c|c|c||}
\hline Comp/ligands & E. coli & $\begin{array}{c}\text { Pseudomona } \\
\text { saeroginosa }\end{array}$ & S.aurous & Klepsiella \\
\hline L1 & 16 & 20 & 16 & 20 \\
\hline L1Co & 10 & 10 & 8 & 12 \\
\hline L1Ni & 12 & 10 & 14 & 16 \\
\hline L1Cu & 8 & 6 & 10 & 12 \\
\hline L1Zn & 10 & 8 & 10 & 18 \\
\hline L2 & 12 & 10 & 14 & 10 \\
\hline L2Co & 8 & 20 & 20 & 8 \\
\hline L2Ni & 10 & 26 & 20 & 10 \\
\hline L2Cu & 8 & 22 & 10 & 10 \\
\hline Amoxicillin & 8 & 6 & 10 & 8 \\
\hline
\end{tabular}

الصور (1,2,3,4 تبين تأثير المعقدات المحضرة في دراستنا على أنواع مختلفة من البكتريا الممرضة للانسان .

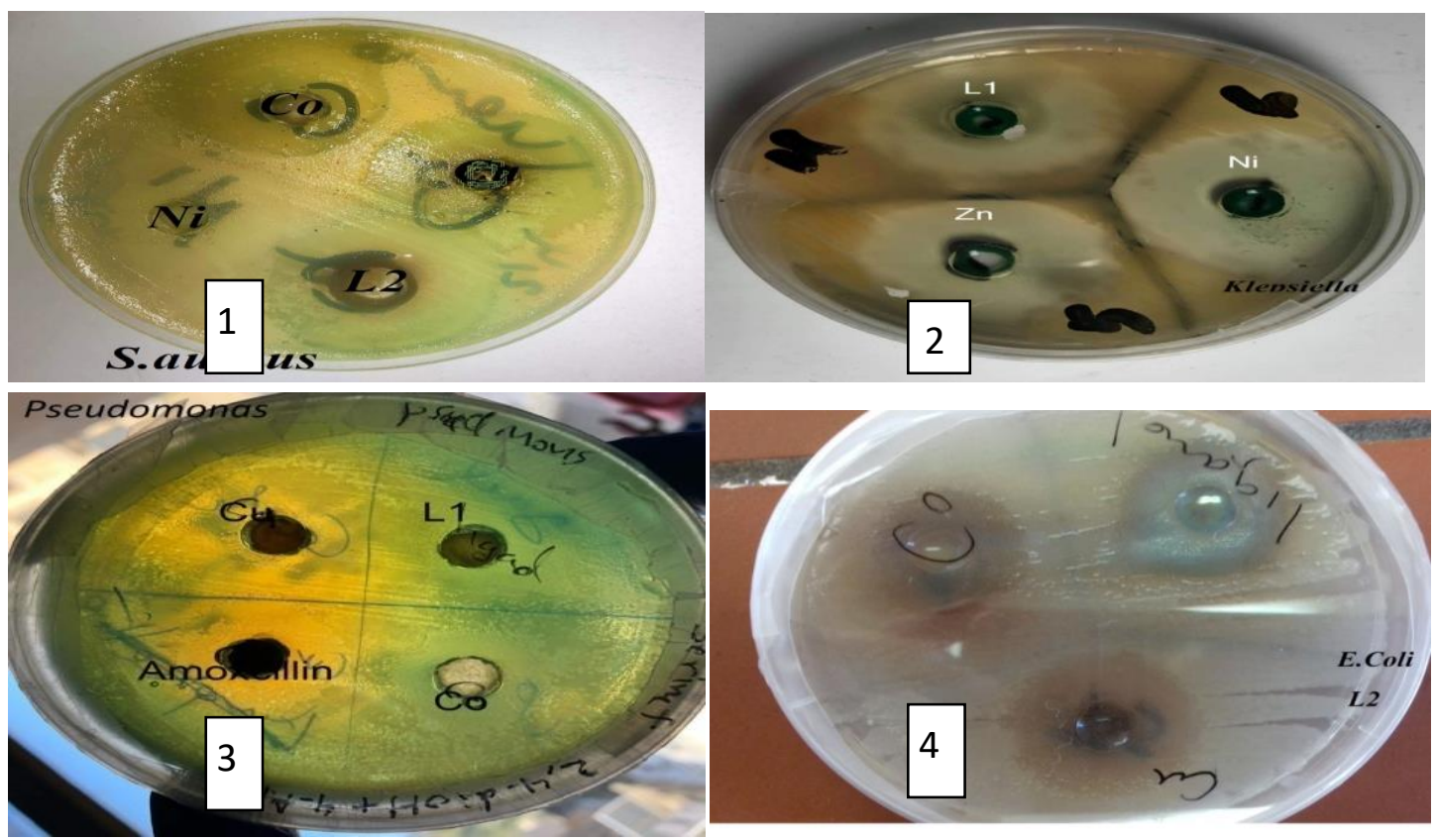

Conclusions 11 الاستنتاجات

أظهرت الدراسات الطيفية (IR) والمغناطيسية والتحليل الدقيق للعناصر لكل من الليكاندات و للمعقدات

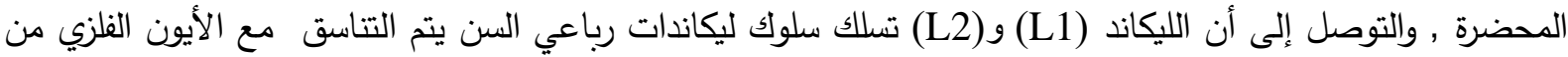

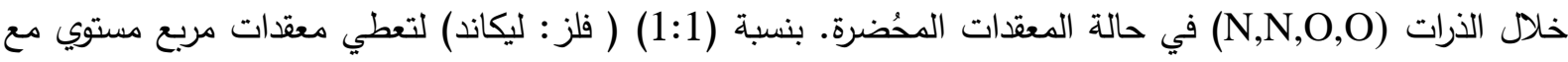
جميع الفلزات باستثناء ايونين الخارصين و الكادميوم يكون كل منهما ذي شكل هندسي رباعي السطوح , فيما يخص الفعالية البيولوجية كانت الليكاندات والمعقدات المحضرة ذات فعالية بكتيرية أعلى من المواد القياسية (Amoxicillin). 


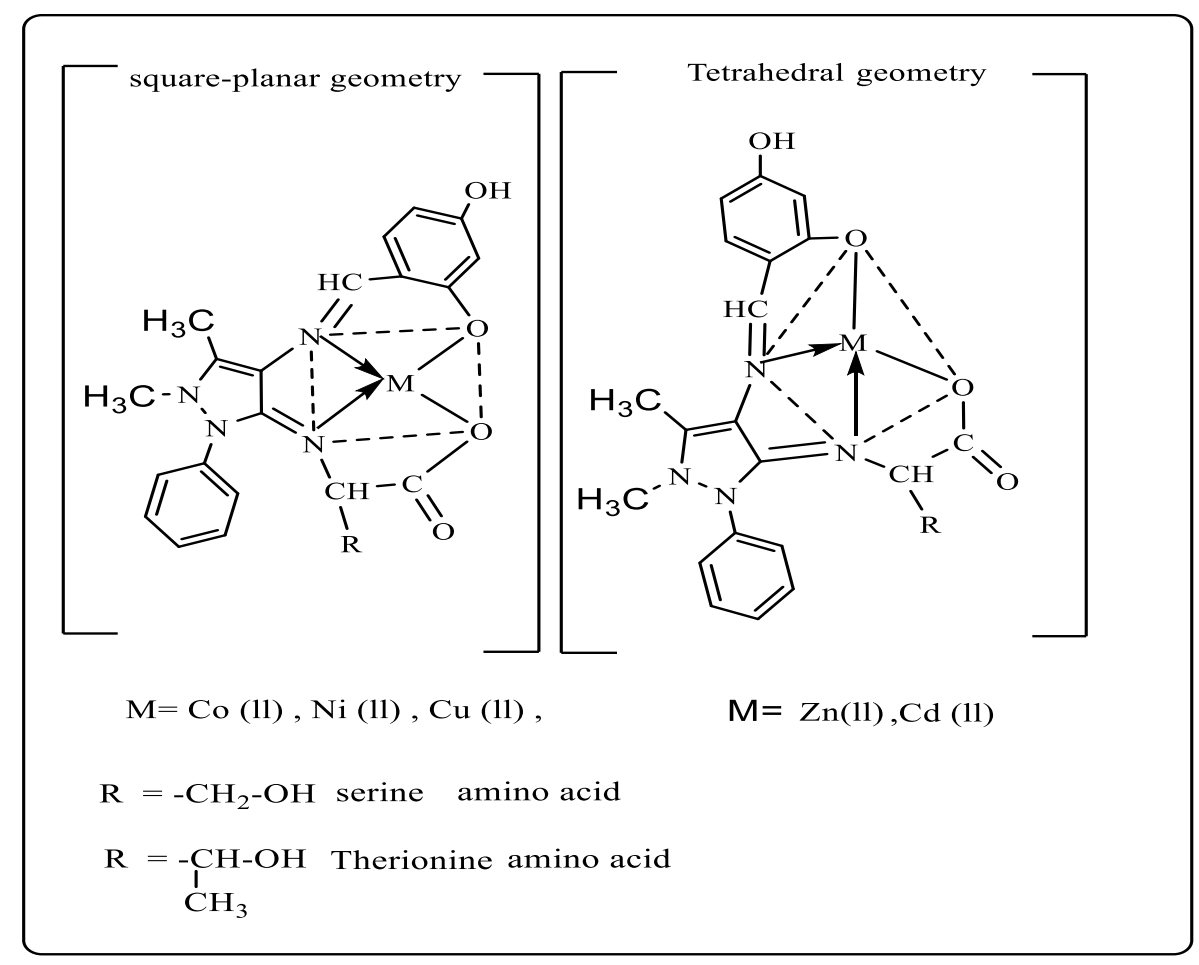

\section{REFERENCES}

(1). Bondock S, Rabie R, Etman HA, Fadda AA.. European journal of medicinal chemistry. (2008);43(10):2122-9.

(2). Abdel-Aziz M, Abuo-Rahma GE, Hassan AA. European journal of medicinal chemistry.( 2009);44(9):3480-7

(3 ). Prachayasittikul V, Prachayasittikul S, Ruchirawat S, Prachayasittikul V . Drug design, development and therapy. (2013);7:1157

(4 ) . Anupama, B., and C. Gyana Kumari. " Research Journal of Pharmaceutical, Biological and Chemical Sciences 2 (2011): 140-159.

(5). Chira Varadarajra, G,Tamilselvan,,IVMV Enoch and Paulraj Mosae Selvakumar(2018), " J., ISSN 2474- 7616,vo1.5 . Isuue2

(6). N. Raman, S. Sobha, Spectrochim. Acta Part A Mol. Biomol. Spectrosc .85 (2012) 234223.

(7). Raman, N., S. Sobha, L. Journal of Saudi Chemical, Society150-151-17 (2013).

(8). Thavuduraj Kavitha, Antonysamy Kulandaisamy, and Ponnusamy.Thillaiarasu, International Journal of ChemTech Research Vol.4, No.4, pp 1571-1581, (2012). 
(9) . Palanimurugan, A., and A. Kulandaisamy. " Journal of Organometallic Chemistry 861 (2018)

(10) . I. Gamo, J, Bull. Chem. Soc., 34,760,1430(1961).

(11) K.Nakamoto.Infrared and Raman Spectra of Inorganic and Coordination compounds. 5th Ed.,Wiley-Inter Science Publication, New York,part B,42(1997)

(12) . K.Nakanishi , "Infrared Absorption Spectroscopy ", $1^{\text {st }}$ ed Nankodo Jopan , 38 , 39 $52,(1962)$.

(13). Nishida and S.Kida " Journal of Inorganic and Nuclear Chemistry.7,325,(1971).

(14). M.S.Iqbal, S.J.Khurshid and B.Muhammad, Medi. Chem.Rese, 22(2),861 868, (2013).

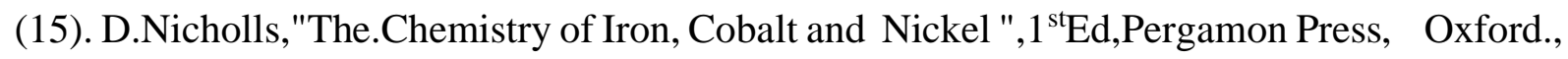
1090, (1973)

(16). F.A.Cotton and G. Wilkinson,"Advanced Inorganic Chemistry" $5^{\text {th }}$. Ed., Interscience, New Yourk, (1988).

(17) . F.A.Cotton and G. Wilkinson,"Advanced Inorganic Chemistry" $5^{\text {th }}$. Ed., Interscience, New Yourk, (1988).

(18). J.C.Bailar and G.R.Urbana, "Comprehensive Inorganic Chemistry $1^{\text {st }}$. Ed., 1090, (1973).

(19). B.N.Figgis"Introduction to Ligands Field",Interscience New York258, 319,(1967).

(20). A.Qatto , S.Yamal , "An elements of Magnetic Chemistry " , $2^{\text {nd }}$ Ed.East West NewDelni $, 101,(1993)$.

(21) . R.C. Aggawal, N. Sigh and S. Singh, , Abst., 75. Polyhydron, 4, 343, and (1985),

(22). M. Arshad,Saeed-ur-Rehman and others, Turk. J.Chem., 32, (2008), 593-604

(23). - Kusmariya, Brajendra S., Journal of Molecular Structure 1116 (2016): 279-291.

(24) . Arshad, Muhammad, Turkish Journal of Chemistry 32.5 (2008): 593-604.

(25). Foziah A. Al-Saif, Int. J. Electrochem. Sci., 8 (2013) 10424 -10445

(26). S.N. Chaulia , Der Pharmacia Lettre, (2016), 8 (21): 55-74.

(27). B .D, Elements of X-ray Diffraction Philippines, second ed Addison,Wesley;(1978).

(28). C. Anderson and S. Cockayane, "Clinical Chemistry :Concepts and Applications",1 st Ed., W.B. Saunders Company, 417(1993).182. 
(29 ) .L.M., Prescott, J.P. Harley and D.A., Klein.. " Microbiology " 3 rd ed Wm.C. Brown, Publicher, London, pp. 436-450(1996)

(30) Paynter DI, Moir RJ, Underwood EJ. J Nutr (1979):1570-1576

(31). Swati, Manu Gupta, RomilaKarnawat, IK Sharma, PS Verma Research Journal of Pharm, Bio and Chem, Sci., Vol. 2, No. April - June (2011),805- 811 